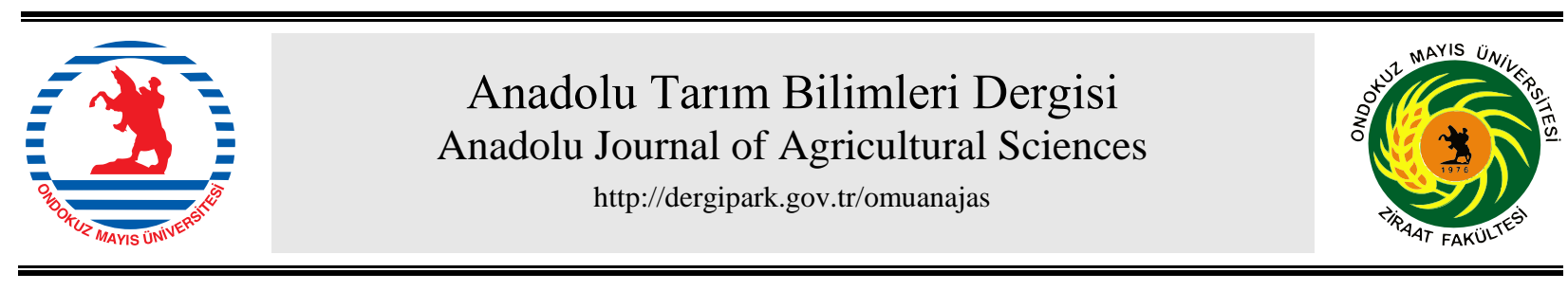

Araştırma/Research

Anadolu Tarım Bilim. Derg./Anadolu J Agr Sci, 33 (2018)

ISSN: 1308-8750 (Print) 1308-8769 (Online) doi: 10.7161/omuanajas.329204

\title{
Gökçeada topraklarının erozyon duyarlılığı
}

\author{
Remzi İlay*, Yasemin Kavdır \\ Çanakkale Onsekiz Mart Üniversitesi, Ziraat Fakültesi, Toprak Bilimi ve Bitki Besleme Bölümü, 17020 Çanakkale/Türkiye \\ "Sorumlu yazar/corresponding author: rilay@comu.edu.tr
}

Geliş/Received 18.07.2017～Kabul/Accepted 12/01/2018

\begin{abstract}
ÖZET
Gökçeada, organik tarım uygulamaları açısından ülkemizdeki en uygun bölgelerden biri olup "organik tarım adası" olarak ünlenmiştir. Gökçeada'da doğal kaynakların kalitesinin korunmasına yönelik tespitlerin yapılarak gerekli önlemlerin alınması gerekmektedir. Ekosistemin sürdürülebilirliği için toprak, en temel doğal kaynaklardan biridir. Toprak kalitesinin sürdürülebilir olması için öncelikle toprağın korunarak mevcut durumunun belirlenmesi ve varsa risklerin de belirlenerek gerekli önlemlerin alınması gerekmektedir. Bu çalışmada Gökçeada topraklarının erozyona duyarlılığının (erodibilitesinin) RUSLE modelinde belirtildiği şekilde tespit edilmesi amaçlanmıştır. Bu amaçla arazi kullanımı ayırmaksızın 248 farklı noktadan yüzey toprak örneği alınmış ve gerekli analizler yapılmıştır. Gökçeada toprakları genel olarak değerlendirildiğinde RUSLE-K değerlerinin 0 ila 0.65 arasında değiştiği, ortalamanın ise 0.25 olduğu ve Gökçeada topraklarının yaklaşık \% 52'sinde orta, yüksek ve çok yüksek düzeyde erozyon riski bulunduğu belirlenmiştir.
\end{abstract}

\section{Soil erodibilty of Gökçeada}

\section{ABSTRACT}

Gökçeada is one of the most suitable regions for organic farming practices in our country and known as "organic agriculture island ". In Gökçeada, necessary measures must be performed to protect the quality of natural resources by making determinations. Soil is one of the main natural sources for ecosystem sustainability. In order to obtain sustainable soil quality, soil must be conserved and current situation risks should be determined, and then necessary precautions must be taken. In this study, it is aimed to determine the erosion sensitivity (erodibility) of Gökçeada soil as specified in the RUSLE model. For this purpose, soil samples were taken from 248 different locations of Gökçeada and necessary soil analyzes were carried out. It was determined that the RUSLE-K values ranged from 0 to 0.65 and the mean value was 0.25 . There was a medium, high and very high level of erosion risk in about $52 \%$ of the Gökçeada soil.

Anahtar Sözcükler:

Gökçeada

Erozyon

RUSLE-K

Toprak

\section{Giriş}

Gökçeada, konumu, doğası, doğal kaynakları gibi çeşitli özellikleri bakımından yüksek organik tarım potansiyeline sahip alanlardan biridir. Resmi kurumların kalkınma planlarında, adaya yönelik planlamaların ve ilginin artmasıyla, adanın potansiyeli daha fazla fark edilir duruma gelmiştir. Bununla birlikte adanın ekolojik turizme kazandırılması için stratejik planlamaların devam etmekte olduğu bilinmektedir. Gökçeada ekonomisi, öncelikli olarak turizm, tarım ve hayvancılığa dayanmaktadır. Buna bağlı olarak adanın potansiyelini kullanmak adına yapılacak planlamalarda, toprak ve toprağın korunmasına yönelik çalışmalar bölge ve ülkemiz için stratejik önem taşımaktadır.
Gökçeada' nın arazi yapısı, özellikle de eğim durumu göz önünde bulundurulduğunda, yüksek toprak erozyonu risk potansiyeline sahip olduğu açıktır. Topoğrafya, bitki örtüsü, iklim ve canlılar gibi erozyona etki eden faktörlerle birlikte toprak özelliklerinin de erozyon üzerine etkisi oldukça büyüktür. $\mathrm{Bu}$ sebeple toprağın iç dinamiklerine bağlı erozyona duyarlılığının durumu ve derecesinin bilinmesi de oldukça önemlidir.

Toprak kayıplarının hesaplanması ve değerlendirilmesine yönelik yapılan çalışmalarda, birçok faktör girdisinden yararlanılarak oluşturulmuş çeşitli modeller kullanılabilmektedir. Üniversal toprak kaybı modeli (USLE), 1978 yılında artan tarımsal uygulamalar sonucundaki toprak kayıplarıyla ilgili olarak Amerika Birleşik Devletleri'nde uzun dönemde 
su erozyonu tahmini için tasarlanmış parsel-tarla ölçekli olarak geliştirilmiş en yaygın modeldir ve bu amaçla tasarlanmış ilk ampirik model olma özelliğindedir (Wischmeier ve Smith, 1978). USLE modelinin amac1 toprakların parmak ve yüzey erozyonundan korunması amaciyla erozyonu önceden tahmin etmektir (Lal, 1999). USLE modelinin tekrar düzenlenip yenilenmesi ile revize edilmiş üniversal toprak kaybı modeli (RUSLE) 1. Versiyonu (Renard ve ark., 1997) ve 2. Versiyonu (Foster, 2005) ortaya çıkmıştır. Avrupa düzeyinde ise (Panagos ve ark., 2012), toprak tekstürü ve organik karbon verilerini (LUCAS veritabanından) ve orijinal nomogramı kullanarak toprak erodibilitesini tahmin etmiştir.

Toprak erodibilite faktörü, USLE modelinde $\mathrm{K}$ faktörü olarak belirtilmektedir. Toprak erodibilitesi toprağın aşınmaya, sıçramaya, sürüklenmeye karşı doğasındaki dirençtir. $\mathrm{Bu}$, toprak partiküllerinin arasındaki kohezif kuvvetlerle ilgilidir. Kohezif kuvvetler bitki örtüsü, toprak nem içeriği, toprak strüktürünün dayanıklılığına göre değişebilmektedir. K faktörü, toprak-aşınabilirlik nomogramı veya denklemi kullanılarak belirlenmekte (Wischmeier ve ark., 1971) olup çeşitli şekillerde değerlendirilebilmektedir (Çizelge $1)$.

Çizelge 1. Bazı RUSLE-K faktörü değerlendirme sinıflar1

\begin{tabular}{ll|ll}
\hline $\begin{array}{l}\text { Dangler ve ark. (1976)'dan } \\
\text { (Modifiye edilmiş) }\end{array}$ & \multicolumn{2}{|l}{ Pauwelsve ark. (1980) } \\
\hline Sinıf & K-Faktör & Sinıf & $\begin{array}{l}\text { K- } \\
\text { Faktör }\end{array}$ \\
\hline Çok düşük & $0-0.10$ & $\begin{array}{l}\text { Düşük-çok } \\
\text { düşük }\end{array}$ & $0-0.25$ \\
Düşük & $0.10-0.20$ & Orta & $0.25-$ \\
& $0.20-0.30$ & Yüksek & 0.35 \\
Orta & $0.30-0.40$ & Çok yüksek & 0.45 \\
Orta-yüksek & $0.45+$ \\
Yüksek & $0.40-0.50$ & & \\
Çok yüksek & $0.50+$ & & \\
\hline
\end{tabular}

Gökçeada'da jeomorfolojik ve topoğrafik özelliklerine bağlı olarak yüksek erozyon potansiyelinin olduğu alanlar rapor edilmiştir (KHGM, 1999). Ancak adadaki yağış, topoğrafik/jeolojik durum ve bitki örtüsü gibi erozyon şiddetini etkileyen faktörlerin yanında toprak özellikleri kullanılarak tespit edilen toprak erodibilitesinin ( $\mathrm{K}$ faktörü) belirlenerek, toprak kaynaklarının korunması ve sürdürülebilirliği için gerekli tedbirlerin alınması önem teşkil etmektedir.

Bu çalışma adanın tamamını kapsamakta olup, farklı noktalardan 248 adet $0-20 \mathrm{~cm}$ derinlikten yüzey toprağ 1 alınmıştır. Alınan toprak örneklerinde $\mathrm{K}$ faktörünün tespiti için gerekli fiziksel ve kimyasal toprak analizleri yapılarak değerlendirmelerde bulunulmuştur.

\section{Materyal ve Yöntem}

\section{1. Çalı̧̧ma alanınin genel tanıtımı}

Gökçeada, kuzey Ege Denizi'nin $25^{\circ} 40^{\prime} 06^{\prime}$ '- $26^{\circ}$ $01^{\prime} 05^{\prime \prime}$ doğu boylamları ile $40^{\circ} 05^{\prime} 12^{\prime \prime}$ - $40^{\circ} 14^{\prime} 18^{\prime}$ " kuzey enlemleri arasında ve Çanakkale'nin $40 \mathrm{~km}$ batısında yer almaktadır. Gökçeada'nın kıyı uzunluğu da 95 km'dir ve yüzölçümü yaklaşı $286 \mathrm{~km}^{21}$ dir. Ada, merkez ilçeye bağli 9 köy ve ilçedeki 3 mahalleden oluşmaktadır. Su kaynakları açısından zengin adada 5 adet gölet bulunmaktadır. Akdeniz iklimi etkisi altında olan Marmara geçiş iklim tipi görülmektedir.

Gökçeada'nın kuzeybatısında bulunan Semadirek Adası'na uzaklığı yaklaşık $22 \mathrm{~km}$, güneybatısındaki Limni Adası' na ise uzaklığı yaklaşı $18 \mathrm{~km}$ ' dir. Gökçeada engebeli bir arazi yapısına sahiptir. \% 64.72's1 \% 12 üzerinde eğim değerlerine sahipken, $\%$ 13.63'ü düz-düze yakın alanlardan oluşmaktadır (İlay, 2016). $678 \mathrm{~m}$ yüksekliği bulunan Doruk Tepe adanın en yüksek noktasıdır. Adada yaygın olarak bitki örtüsü orman ve maki görülse de zeytinlikler de bulunmaktadır. Gökçeada, volkanik kütlelerden oluşmuştur (Şekil 1).
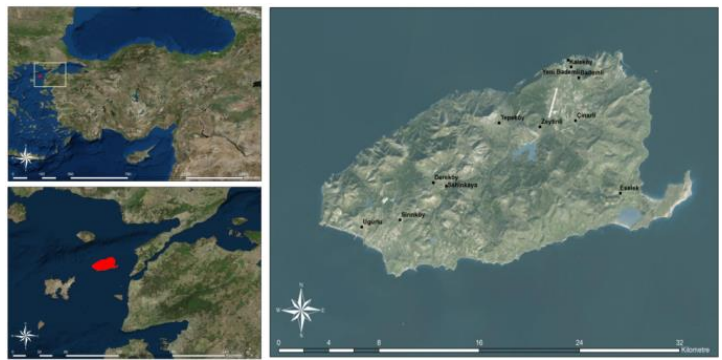

Şekil 1. Gökçeada'nın coğrafi konumu

\subsection{Toprakların örnekleme noktalarınin belirlenmesi ve örneklerin alınmast}

Örnekleme noktaları, adaya ait topoğrafik haritalardaki eğim grupları, toprak haritasındaki büyük toprak grupları ve alt gruplar ile arazinin drenaj deseni dikkate alınarak önceden belirlenmiş sonrasında bu noktalara ait koordinatlar GPS (Global Positioning System)'e aktarılmıştır. Koordinatları bilinen örnekleme noktalarına ait alanların tamamından arazi koşullarının olumsuz olması (yüksek eğim, yasaklı bölgeler v.b.) nedeniyle örnekleme yapılamamış olup, arazi koşullarının uygun olduğu 248 noktaya ait alandan yüzey toprăg $1(0-20 \mathrm{~cm})$ örneklenmiştir. Aynı zamanda örneklemelere ait koordinatlar GPS'e kaydedilmiştir. Örnekleme noktalarına ait harita ise Şekil 2'de gösterilmiştir. 


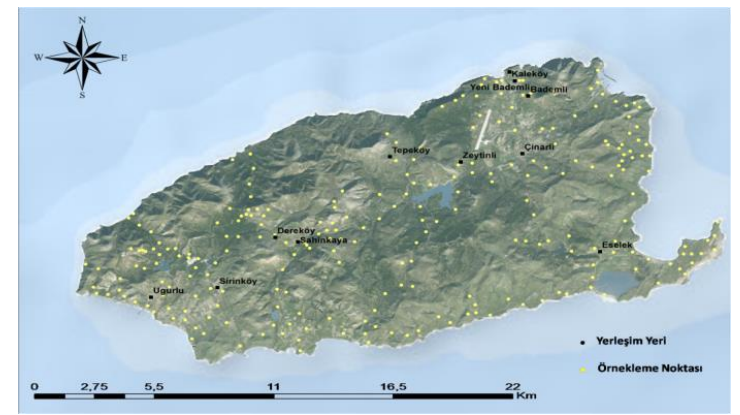

Şekil 2. Çalışma kapsamında örneklenen noktaların dağılımı

\subsection{Toprak örneklerinin fiziksel ve kimyasal analizleri}

Alınan topraklar analizlere hazırlık öncesinde hava kuru hale gelmesi için örnek hazırlama odasına serilmiş̧ir. Örneklerin strüktür tipleri arazide belirlenmiştir. Toprak örneklerinin öğütülen kısmı 2 mm'lik elekten elenmiş ve plastik poşetler içinde saklanmıştır. Toprakların organik madde kapsamları toplam karbonun LECO marka Truspec CN cihazında kuru yakılması sonucu elde edilen değer ve inorganik karbon kapsamları kullanılarak tespit edilmiştir. Toprak tane irilik dağıllımı (toprak tekstürü), $2 \mathrm{~mm}$ 'lik elekten elenmiş toprak örneklerinde Bouyoucos (1951)'de belirtilen esaslar temel alınarak hidrometre yöntemiyle yapılmıştır. Hidrometre okumalarından sonra tekstür silindirindeki materyalin tümü $0,1 \mathrm{~mm}$ 'lik elekten geçirilmiş ve elek üstünde kalan kısım etüvde kurutulmuştur. Sonrasında tartımı yapılan kısım (kaba kum), hesaplaması yapılan toplam kum miktarından çıkarılarak çok ince kum belirlenmiştir. Strüktür tipleri arazide tespit edilerek, çok ince granüler (1), ince granüler (2), orta-kaba granüler (3) ve blok, levhalı, masif (4) şeklinde kodlanmış ve hesaplamada kullanılmıștır. Toprakların geçirgenlik sınıfları, tekstür analizi sonucunda tespit edilen tekstür sinıfları dikkate alınarak Soil Survey Staff, (1983)'e göre belirlenmiştir.

\subsection{Toprak erodibilitesinin (K-Faktörü) bulunması ve haritalanmasl}

K-Faktörü, silt, çok ince kum, kil içeriği ile birlikte, OM (Organik Madde) içeriği, yüzey strüktürü ve geçirgenliği ile aşağıdaki eşitlik kullanılarak matematiksel olarak hesaplanmıştır (Wishmeier ve Smith, 1978).

$$
\begin{aligned}
\mathrm{K} & =\left[2.1 \mathrm{~m}^{1.14}\left(10^{-4}\right)(12-\mathrm{a})+3.25(\mathrm{~b}-2)+2.5(\mathrm{c}-3)\right] / 100 \\
\mathrm{~K} & =\text { Toprak erodibilite faktörü (U.S.) } \\
\mathrm{m} & =(\text { silt }(\%)+\text { çok ince kum }(\%))(100-\mathrm{Kil}(\%)) \\
\mathrm{a} & =\text { Organik madde }(\%) \\
\mathrm{b} & =\text { Toprak strüktür sınıfı } \\
\mathrm{c} & =\text { Geçirgenlik sınıfı }
\end{aligned}
$$

Çalışma kapsamında alınan toprakların erozyona duyarlılığın çalışma alanında konumsal olarak nasıl değiştiğini belirlemekiçin ARCGIS 10.0 yazılımı kullanılarak tematik harita oluşturulmuştur. Her örnekleme noktasında hesaplanan $\mathrm{K}$ faktörü değerleri Simple Kriging yöntemi kullanılarak örneklenmemiş alanlar için $\mathrm{K}$ faktör değeri tahmini yapılmış ve raster harita oluşturulmuştur (Şekil 3).

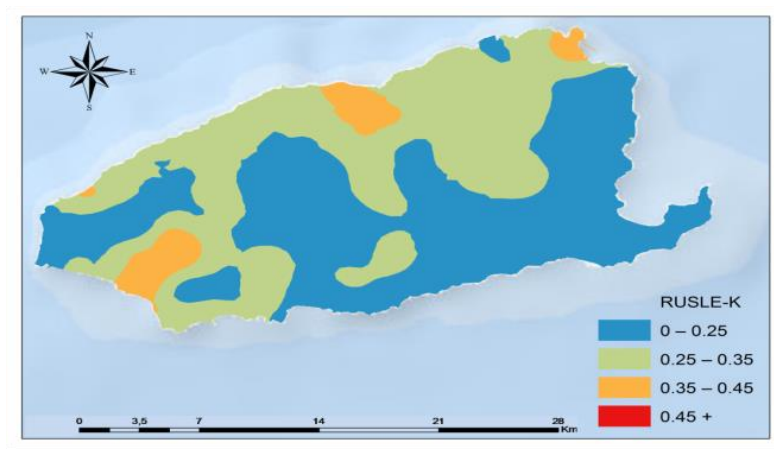

Şekil 3. Gökçeada topraklarının erozyon risk durumu (RUSLE-K) haritas 1

\section{Bulgular ve Tartışma}

Alınan toprak örneklerinde K-Faktörünün hesaplanmasında kullanılacak bazı analizlere ait değerler Çizelge 2'de verilmiştir. Analizleri yapılan toprakların kil, silt, çok ince kum ve kum fraksiyonları tespit edilmiştir. Çizelge $2^{\prime}$ de sunulduğu üzere; kil miktarının \% 3.23 ile \% 64 arasında değiştiği ortalamanın \%22.94olduğu görülmektedir. Bununla birlikte silt içeriği \% 1.28 ile \% 75.72 arasında olup ortalaması \% 29,40’tır. Toprakların kum içeriklerine bakıldığında \% 11.44 ile \% 92.79 olup, ortalama \% 47.66 olarak bulunmuştur. Toprak erodibilitesinin hesaplamasında kullanılmak üzere topraklarda tespit edilen çok ince kum içerikleri ise \% 1.58 ile \% 44.53 arasında değişmekte olup ortalaması \% 19.95'tür.

Alınan 248 toprak örneğinin arazi örtüsü fark etmeksizin TOK (Toprak Organik Karbonu) kapsamları incelendiğinde; en yüksek değerin $\% 6.32$ en düşük değerin \% 0.9 olduğu, ortalamanın ise \% 2.11 olduğu tespit edilmiştir (Çizelge 2). Tekstür analizine göre bünye sınıfları belirlenmiş ve bu sınıflardan yararlanılarak tespit edilen geçirgenlik sinıfları belirlenmiştir. Buna göre toprak örneklerinin \% 49.60'1 orta-yavaş, $\% 25.81$ 'i orta, \% 17.74'ü orta-hızlı sınıfinda yer alırken \% 1.21 'i yavaş sınıfina dahil olduğu belirlenmiştir. Örneklenen noktalardaki toprakların \% 95.16'sının strüktür tipi ince ve orta-kaba granüler olarak tespit edilmiştir. 11 örnekleme noktasında çok ince granüler, 1 örnekleme noktasında ise levha strüktür tipi tespit edilmiştir.

248 toprak örneğinde yapılan tüm bu analizler ve veriler kullanılarak hesaplanan RUSLE-K değerlerinin 0 ila 0.65 arasında değiştiği, ortalamanın ise 0.25 olduğu görülmektedir (Çizelge 2). Pauwelsve ark. (1980) göre 
yapılan değerlendirmede, toplam 248 örnek noktasının, 161 'inin düşük, 42 'sinin orta, 23'ünün yüksek ve 22 örnek noktasının ise çok yüksek derecede erozyon riskine sahip olduğu tespit edilmiştir. Genel olarak değerlendirildiğinde toplam örnek sayısının \% 35.08'i orta, yüksek ve çok yüksek erozyon riskine sahip olduğu belirlenmiştir.

Çizelge 2. Toprak örneklerinde belirlenen parametrelere ait bazı değerler (en küçük, en büyük, ortalama ve standart hata değerleri, $(n=248)$, \pm : Standart Hata)

\begin{tabular}{lcccc}
\hline Parametreler & $\begin{array}{c}\text { En } \\
\text { Küçük }\end{array}$ & $\begin{array}{c}\text { En } \\
\text { Büyük }\end{array}$ & \multicolumn{2}{c}{ Ortalama } \\
\hline Kil (\%) & 3.23 & 64.00 & $22.94 \pm 0.64$ \\
Silt (\%) & 1.28 & 75.72 & $29.40 \pm 0.93$ \\
Kum (\%) & 11.44 & 92.79 & $47.66 \pm 0.97$ \\
Kaba Kum (\%) & 1.93 & 91.18 & $27.72 \pm 0.99$ \\
Çok İnce & 1.58 & 44.53 & $19.95 \pm 0.45$ \\
Kum (\%) & & & & \\
TOK (\%) & 0.90 & 6.32 & $2.11 \pm 0.05$ \\
RUSLE-K & 0.00 & 0.65 & $0.25 \pm 0.01$ \\
\hline
\end{tabular}

Şekil 3'te Gökçeada'dan alınan toprak örneklerinin RUSLE-K değerlerine göre hazırlanan erozyona duyarlıl1k durumunu gösteren harita sunulmuştur. Buna göre adanın kuzey kesimindeki topraklarında güneyine oranla erozyon riski daha yüksektir. Yöney ve yağış ilişkileri değerlendirildiğinde adanın kuzey kesiminde kuzey yöneylerin ve yüksek eğim gruplarının daha yoğun olduğu (İlay, 2016), bu sebeple $\mathrm{K}$ faktörü hesaplamasında kullanılan bileşenlerin yağış-yöney ilişkisi çerçevesinde daha fazla etkilenebileceği düşünülmektedir. Buna paralel olarak güney kesimlerindeki toprakların kil miktarının daha yüksek, silt miktarının daha düşük olduğu, ayrıca örneklerin kil içerikleri ile RUSLE-K arasında negatif bir ilişkinin $(\mathrm{p}<0.01)$; silt miktarı ile RUSLE-K arasındaki ilişkinin ise pozitif $(\mathrm{p}<0,01)$ olduğu bildirilmiştir (İlay, 2016). Çizelge 3 'te risk haritasının alansal dağılım oranları incelendiğinde, ada topraklarının \% 48'i düşük, \% 39'u orta, \% 12'si yüksek ve \% 0.1'nin çok yüksek erozyon tehlikesi altında olduğu görülecektir.

Çizelge 3. Gökçeada topraklarının erozyon riski bakımından alansal dağılımı

\begin{tabular}{lll}
\hline Risk Durumu & Alan (ha) & Oran (\%) \\
\hline Düşük & 13631.42 & 48.17 \\
Orta & 11066.19 & 39.10 \\
Yüksek & 3567.09 & 12.61 \\
Çok Yüksek & 35.30 & 0.12 \\
\hline Toplam & 28300 & 100 \\
\hline
\end{tabular}

İlay (2016), bu çalışmanın da içinde bulunduğu çalışmada arazi örtüsüne göre tespit edilen ortalama RUSLE-K değerlerindeki farkın istatistiki olarak önemli $(\mathrm{p}<0.05)$ olduğunu belirtmiştir. Tarım alanlarındaki erozyon riskinin orman ve yarı doğal olarak kullanılan alanlardan daha yüksek olduğu; ayrıca RUSLE-K değerlerinin bakılan birçok toprak parametresi ile doğrusal pozitif ve negatif ilişkiler içerisinde olduğu tespit edilmiştir.

Kireçli toprakların erodibilitesini tahmin için yapılan çalışmalarda; K faktörünün strüktür ve geçirgenlik üzerine etki eden toprak özellikleriyle ilgili olduğunu göstermiştir (Gupta, 2002; Hoyos, 2005; Summer, 1982). Bazı çalışmalar ise toprak partiküllerinin, organik maddenin, değișebilir potasyum ve demir oksitlerin $\mathrm{K}$ faktörü üzerine direkt etkisinin olduğunu göstermiştir (Auerswald ve ark., 1996; Evrendilek ve ark., 2004; Rhotonve ark., 1998; Rodriguez ve ark., 2006; Santos ve ark., 2003; Veihe, 2002; Zhang ve ark., 2004).

\section{Sonuç}

$\mathrm{Bu}$ çalışmada Gökçeada'daki toprak kaynaklarının korunmas1 ile erozyona duyarlı alanların görsel ve rakamlarla ortaya konulması amaçlanmıştır. Bu amaçla verimlilik ve ekosistem üzerine direkt etkisi olanerozyon hassasiyeti, RUSLE-K faktörü esas alınarak belirlenmiştir. $\mathrm{Bu}$ sonuçlar 1şığında, riskli bölgelerdeki arazi yönetimlerine dikkat edilerek riskin azaltılması için çalışmalar yapılmalıdır. Strüktürel yapının bozulmamasına dikkat edilmelidir. Özellikle tarım arazilerinde agregatlaşmayı bozacak aşırı gübreleme ve sulamadan kaçınılmalıdır. İmkanlar dahilin de başta tarım arazilerine olmak üzere uygulama yapılabilecek diğer arazilere organik madde (yeşil gübre, organik atıklar, hayvan gübresi v.b.) ilavesi yapılmalıdır. Diğer arazilerde ise mevcut durumunun korunarak daha da iyileştirilmesi için çaba harcanmalıdır. Bitki örtüsünün tahribatının engellenmesiyle birlikte arazilerin boş bırakılmaması için alınacak önlemler, sistem için organik madde kaynağ1 olacağ gibi erozyona bağlı kayıpların önüne geçerek toprak kalitesini olumlu yönde etkileyecektir.

\section{Teşekkür}

$\mathrm{Bu}$ çalışmaya sağladığı maddi desteği için, Çanakkale Onsekiz Mart Üniversitesi Bilimsel Araştırma Projeleri Komisyonu'na (2012/17 nolu Doktora Tez Projesi) ve haritalama konusundaki desteği için Dr. Yusuf Yiğini' ye teşekkür ederiz.

\section{Kaynaklar}

Auerswald, K., Kainz, M., Angermüller, S., Steindl, H., 1996. Influence of exchangeable potassium on soil erodibility. Soil Use and Management, 12: 117-121. doi:10.1111/j.1475-2743.1996.tb00531.x. 
Bouyoucos, G.J., 1951. A Recalibration of the Hydrometer Method for Making Mechanical Analysis, Agronomy Journal, Vol. 43, No. 9, 1951, pp. 434-438. doi:10.2134/agronj1951.00021962004300090005x.

Dangler, E.W., El-Swaify, S.A., Ahuja, L.R., Barnet, A.P., 1976. Erodobility of Selected Hawaii Soils by Rainfall Simulation. Ars W-35. Ars/Usda- Univ. of Hawaii Agric. Exp. Stn., Honululu, Hi. doi:10.2136/sssaj1976.03615995004000050040x.

Evrendilek, F., Celik, I., Kilic, S., 2004. Changes In Soil Organic Carbon and Other Physical Soil Properties Along Adjacent Mediterranean Forests, Grass land and Cropland Ecosystems in Turkey. Journal of Arid Environment, 59: 743-752. doi:10.1016/j.jaridenv.2004.03.002.

Foster, G.R., 2005. RUSLE 2.0 sciencedocumentation (Draft). USDA-Agricultural Research Service, Washington, DC.

Gupta, O.P.,2002. Water In Relation to Soils and Plants. Agrobios, India. 31-34.

Hoyos, N., 2005. Spatial Modeling of Soil Erosion Potential In A Tropical Watershed of The Colombian Andes. Catena, 63: 85-108. doi:10.1016/j.catena.2005.05.012.

İlay, R., 2016. Gökçeada Topraklarının Bazı Kalite Parametreleri ve Erozyon Riskinin Belirlenmesi. Çanakkale Onsekiz Mart Üniversitesi Fen Bilimleri Enstitüsü, Doktora Tezi, Çanakkale.

KHGM., 1999. Köy Hizmetleri Çanakkale İl Müdürlüğü, Çanakkale İli Arazi Varlığı, Köy Hizmetleri Genel Müdürlüğü Yayınları, İl Rapor No: 17, Ankara.

Lal, R., 1999. Soil Quality and Soil Erosion. The Soil and Water Conservation Society. Boca Raton, Fla. Crc Press, 1999.

Panagos, P., Meusburger, K., Alewell, C., Montanarella, L., 2012. Soil erodibility estimation using LUCAS point survey data of Europe. Environmental Modelling \& Software, 30: 143-145.doi: 10.1016/j.envsoft.2011.11.002.

Pauwels, J. M., Aelterman, J., Gabriels, D., Bollinne, A., Rosseau, P., 1980. Soil Erodibility Map of Belgium. In De Boodt, M. And Gabriels, D., Editors, Assessment of Erosion. Chichester: J. Wiley. 193-201.

Renard, K.G., Foster, G.R., Weesies, G. A., McCool,
D.K.,Yoder, D.C., 1997. Predicting soil erosion by water: a guide to conservation planning with the Revised Universal Soil Loss Equation (RUSLE) (Vol. 703). Washington, DC: US Government Printing Office.

Rhoton, F.E., Lindbo, D.L., Romkens, M.J.M., 1998. Iron Oxides Erodibility Intractions for Soils of The Memphis Catena. Soil Sci. Soc. Am. J., 62(3): 1693-1703. doi:10.2136/sssaj1998.03615995006200060030x.

Rodriguez, R.R.,Arbelo, C.D., Guerra, J.A., Natario, M.J.S., Armas, C.M., 2006. Organic Carbon Stocks and Soil Erodibility In Canary Islands Andosols. Catena, 66: 228235. doi: 10.1016/j.catena.2006.02.001.

Santos, F.L., Reis, J.L., Martins, O.C., Castanheira, N.L., Serralheiro, R.P., 2003. Comparative Assessment of Infiltration, Runoff and Erosion of Sprinkler Irrigated Soils. Biosystems Engineering, 86(3): 355-364. doi:0.1016/S1537-5110(03)00135-1.

Soil Survey Staff.,1983. National Soils Handbook, Title 430Vi. United States Department of Agriculture, Soil Conservation Service. U.S. Government Printing Office, Washington, D.C.

Summer, R.M., 1982. Field and Laboratory Studies on Alpine Soil Erodibility, Southern Rocky Mountains, Colorado. Soil Use and Management, 7(3): 253-266. doi: 10.1002/esp.3290070304.

Veihe, A., 2002. The Spatial Variability of Erodibility and Its Relation to Soil Types: A Study from Northern Ghana. Geoderma, 106: 101-120. doi:10.1016/S00167061(01)00120-3.

Wischmeier, W.H., Johnson C.B., Cross, B.V., 1971. A soil erodibility nomograph for farmland and construction sites. Journal Soil and Water Consv., 26:189-193.

Wischmeier, W.H., Smith, D.D., 1978. Predicting Rainfall Erosion Losses-A Guide to Conservation Planning. Agricultural Handbook, No. 537. USDA.

Zhang, K.,Li, S., Peng, W., Yu, B., 2004. Erodibility of Agricultural Soils and Loess Plateau of China., Soil Tillage Res., 76: 157-165. doi:0.1016/j.still.2003.09.007. 